\title{
ETIOLOGICAL AGENTS OF BACTERIAL MENINGITIS IN ADULTS AND ANTIBIOTIC SUSCEPTIBILITY OF STREPTOCOCCUS PNEUMONIAE ISOLATED FROM PATIENTS OF REGIONAL SPECIALIST HOSPITAL OF DR. WŁ. BIEGAŃSKI IN ŁÓDŹ
}

\author{
CZYNNIKI ETIOLOGICZNE BAKTERYJNEGO ZOMR U DOROSŁYCH ORAZ OCENA \\ LEKOWRAŻLIWOŚCI STREPTOCOCCUS PNEUMONIAE WYIZOLOWANYCH \\ OD PACJENTÓW WOJEWÓDZKIEGO SPECJALISTYCZNEGO SZPITALA \\ IM. WŁ. BIEGAŃSKIEGO W ŁODZI W LATACH 2009-2016
}

\author{
Regional Specialist Hospital of Wł. Biegański in Łódź \\ Department of Laboratory Diagnostics \\ Wojewódzki Specjalistyczny Szpital im. Wł. Biegańskiego w Łodzi \\ Dział Diagnostyki Laboratoryjnej
}

\begin{abstract}
INTRODUCTION. Bacterial meningitis (BM) is one of the most severe clinical form of infections, which is well known for an acute course and high mortality. Therefore, it is crucial to establish the etiology and antibiotic susceptibility of frequently isolated microorganisms.

AIM. The aim of this study was to present the etiological agents of BM in adults and antibiotic susceptibility of Streptococcus pneumoniae.

MATERIALS AND METHODS. The inpatient medical records with positive results of the cerebrospinal fluid (CSF) samples obtained from the patients of Regional Specialist Hospital of dr Wł. Biegański in Łódź between January 2009 and January 2016 were analyzed.

RESULTS. In total 1303 CSF samples were taken from 863 patients during this study period, of which 130 CSF specimens were positive for bacterial growth. However, 29 of them were recognized as the contamination and rejected. Therefore, 101 bacterial strains isolated from the CSF samples of 96 patients were analyzed. Five patients had the recurrence of BM. S. pneumoniae was the predominant isolated species (36 strains, 35.6\%) which antimicrobial susceptibility results were presented.

CONCLUSIIONS. $S$. pneumoniae was the most common etiological agent of BM in both patient age groups: adults aged $>50$ years and adults aged $20-50$ years. N.meningitidis was isolated most frequent from patients $\leq 50$ years, while $S$. aureus and Gram-negative bacilli were obtained mainly from group > 50 years old. All tested strains of $S$. pneumoniae were sensitive to vancomycin, linezolid, levofloxacin, rifampicin and chloramphenicol. High percentage of fully sensitivity to ceftriakson $(97.2 \%)$ and meropenem $(96.4 \%)$ was observed. Resistance to penicillin was detected in $27.8 \%$ of all strains.
\end{abstract}

Key words: meningitis, cerebrospinal fluid, Streptococcus pneumoniae, antibiotic susceptibility

\section{STRESZCZENIE}

WSTĘP. Bakteryjne zapalenie opon mózgowo-rdzeniowych charakteryzuje się gwałtownym przebiegiem i wysoką śmiertelnością, dlatego istotne znaczenie ma wiedza o czynnikach etiologicznych i lekowrażliwości bakterii.

CEL. Przedstawienie czynników etiologicznych bakteryjnego zapalenia opon mózgowo-rdzeniowych u pacjentów dorosłych oraz lekowrażliwości szczepów Streptococcus pneumoniae wyizolowanych z płynu mózgowo-rdzeniowego. 
MATERIAŁY I METODY. Dane zebrano poprzez retrospektywną analizę wyników posiewów płynu mózgowo-rdzeniowego dorosłych pacjentów hospitalizowanych w Wojewódzkim Specjalistycznym Szpitalu im. Wł. Biegańskiego w Łodzi w latach 2009 - 2016.

WYNIKI. Przebadano 1303 próbki płynu mózgowo-rdzeniowego pobrane od 863 pacjentów, z których 130 próbek było dodatnich. Jednakże 29 próbek PMR odrzucono, uznając jako pewne kontaminacje i ostatecznej analizie poddano 101 szczepów bakteryjnych wyizolowanych ze 101 próbek, pobranych od 96 pacjentów. U 5 pacjentów zaobserwowano nawrót ZOMR. Najczęściej izolowanym gatunkiem, stanowiącym 35,6\% wszystkich szczepów, był Streptococcus pneumoniae (36 szczepów), dla którego wykonano analizę lekowrażliwości.

WNIOSKI. Najczęstszym czynnikiem etiologicznym bakteryjnego ZOMR, zarówno w grupie wiekowej >50 lat, jak i 20-50 lat jest Streptococcus pneumoniae (36,5\%). Neisseria meningitidis częściej izolowano u osób $\mathrm{w}$ grupie $<50$ lat, a Staphylococcus aureus oraz pałeczki Gram-ujemne od pacjentów $>50$ lat. Wszystkie badane szczepy Streptococcus pneumoniae wykazywały wrażliwość na wankomycynę, linezolid, lewofloksacynę, rifampicynę i chloramfenikol. Zaobserwowano wysoki odsetek pełnej wrażliwości wobec ceftriaksonu (97,2\%) i meropenemu (96,4\%). Oporność na penicylinę stwierdzono u 27,8\% szczepów.

Słowa kluczowe: Zapalenie opon mózgowo-rdzeniowych, płyn mózgowo-rdzeniowy, Streptococcus pneumoniae, lekowrażliwość

\section{INTRODUCTION}

Bacterial meningitis (BM) is one of the most severe clinical forms of infection, which is well known for an acute course and high mortality. In addition, this kind of infection may develop a high risk of severe complications. Infection is transmitted via droplets by kissing, close contact with coughing and sneezing, or sharing one cigarette and cutlery with a carrier. The infection can also develop after injury, when the continuity of the nerve tissue is interrupted or less commonly after neurosurgical treatment. Medical progress enables to deploy advanced, often invasive diagnostic and therapeutic techniques, which could extend patient's life. On the other hand, this situation, increases the group of patients susceptible to infection. Moreover, due to inappropriate antibiotic strategy increase resistance among the various bacterial species is still observed. In view of very dangerous repercussions of BZOMR, it is important to quickly recognize the infection and enable effective antibiotic treatment. Therefore, it is crucial to understand the etiology and antibiotic susceptibility of most frequently isolated microorganisms. Streptococcus pneumoniae is indicated as the most common etiological agent of BM, and because of that reason this antibiotic susceptibility has been analyzed in this elaboration.

\section{AIM}

Presentation of the etiological factors of BM in adults and antibiotic susceptibility of $S$. pneumoniae between 2009-2016.

\section{WSTĘP}

Bakteryjne zapalenie opon mózgowo-rdzeniowych (BZOMR) jest jedną z najcięższych postaci klinicznych zakażeń o gwałtownym przebiegu i dużej śmiertelności. Ponadto zachorowania obarczone są ryzykiem ciężkich powikłań. Do zakażenia dochodzi najczęściej drogą kropelkową poprzez pocałunki, bliski kontakt z osobą kichającą lub kaszlącą, używanie wspólnych sztućców lub dzielenie się jednym papierosem z nosicielem. Infekcja może się rozwinąć po urazie, gdy dojdzie do przerwania ciągłości tkanki nerwowej lub rzadziej, podczas zabiegu neurochirurgicznego. Postęp medycyny, umożliwia wdrażanie zaawansowanych, często inwazyjnych technik diagnostycznych i terapeutycznych, co z jednej strony wydłuża czas życia, ale z drugiej zwiększa grupe pacjentów o podwyższonym ryzyku wystąpienia infekcji. Ponadto razem na skutek niewłaściwej polityki antybiotykowej obserwuje się ciągły wzrost lekooporności wśród różnych gatunków bakterii.

$Z$ uwagi na bardzo niebezpieczne następstwa BZOMR, istotne jest szybkie rozpoznanie zakażenia oraz włączenie skutecznej antybiotykoterapii. Dlatego kluczowe znaczenie ma wiedza o etiologii i aktualnej lekowrażliwości najczęściej izolowanych drobnoustrojów. Jako najczęstszy czynnik BZOMR wskazywany jest Streptococcus pneumoniae, którego lekowrażliwość przeanalizowano $\mathrm{w}$ tej pracy.

\section{CEL PRACY}

Przedstawienie czynników etiologicznych BZOMR u dorosłych w latach 2009-2016 w Wojewódzkim Specjalistycznym Szpitalu im. Wł. Biegańskiego w Łodzi oraz ocena lekowrażliwości szczepów S. pneumoniae. 


\section{METHODS}

The analysis was based on a review of adult patients medical history, who had positive result of the cerebrospinal fluid (CSF) culture between January 2009 and January 2016 in the Dr. Wł. Biegański Regional Specialist Hospital in Łódź. Only adult patients over the age of 20 years old were included in this study, on the basis of their microbiological and analytical examination of the CSF, which indicated BM. Cases with fungal meningitis were excluded. Bacterial strains, which were cultured from the same patient during the same hospitalization, were counted once.

\section{Microbiological analyse of CSF sample}

The first part of CFS sample was used to analytical examination and the second part, after centrifuged was cultured on Columbia Agar, Chocolate Agar, brainheart infusion broth and pediatric medium BACTEC (Becton Dickinson), which was incubated in automatic system of detection during 5 days. Simultaneously, a smear [...] microscopy using Gram staining method was directly performed. The supernatant was used to agglutination method according to the manufacturer's instruction (bioMerieux, BioRad, Becton Dickinson).

\section{Species identification}

All strains were identified by colonial morphology, Gram stain, oxidase test, and then to the species level by Vitek2Compact (bioMerieux) according to the manufacturer's instruction.

\section{Susceptibility testing of Streptococcus pneumoniae:}

Susceptibility testing was performed using disc diffusion method and minimal inhibitory concentration (MIC). The results of the antibiotic susceptibility were interpreted according to European Committee on Antimicrobial Susceptibility Testing (EUCAST) ver. 7.1. guideline.

The analysis was based on a retrospective review of patients for whom laboratory testing of CSF was positive. Antibiotic susceptibilityresults to penicillin, ceftriaxone, meropenem, vancomycin, co-trimoxazole, levofloxacin and chloramphenicol were performed. Part of the strains was not tested for their susceptibility to all antibiotics which were presented in the analysis. Susceptibility to penicillin and ceftriaxone was always made by the Etest method, whereas susceptibility to the rest of antibiotics was evaluated using interchangeably both of two methods - disc diffusion and the Etest (bioMerieux, Liofilchem, Oxoid). Quality control strain used for testing antimicrobial susceptibility of pneumococci was S. pneumoniae ATCC 49619.

\section{MATERIAŁY I METODY}

Dane zebrano poprzez retrospektywną analizę dodatnich wyników posiewów płynu mózgowo-rdzeniowego (PMR) pacjentów hospitalizowanych w Wojewódzkim Specjalistycznym Szpitalu im. Wł. Biegańskiego w Łodzi w latach 2009 - 2016. Analiza obejmowała tylko pacjentów od 20 roku życia, u których na podstawie hodowli mikrobiologicznej oraz badania ogólnego PMR wykryto bakteryjne zakażenie układu nerwowego. Przypadki o etiologii grzybiczej zostały pominięte. Szczepy wyhodowane od tego samego pacjenta, podczas tej samej hospitalizacji, zostały policzone jeden raz.

\section{Badanie mikrobiologiczne próbki PMR}

Pierwsza część próbki PMR została przeznaczona do badania ogólnego, a druga po odwirowaniu została posiana na podłoże Columbia, agar czekoladowy, bulion mózgowo-sercowy oraz podłoże płynne BACTEC (Becton Dickinson), które było inkubowane w systemie automatycznym przez 5 dni. Jednocześnie z osadu wykonano preparat mikroskopowy barwiony metodą Grama. Z supernatantu wykonano test aglutynacji szkiełkowej zgodnie $\mathrm{z}$ instrukcją producenta (bioMerieux, BioRad, Becton Dickinson).

\section{Identyfikacja szczepów:}

Wszystkie szczepy były identyfikowane na podstawie morfologii kolonii, preparatu mikroskopowego, testu wykrywającego oksydazę cytochromową, a następnie do gatunku za pomocą analizatora Vitek2Compact (bioMerieux).

Oznaczanie lekowrażliwości Streptococcus pneumoniae:

Oznaczanie lekowrażliwości wykonano za pomocą metody dyfuzyjno-krążkowej oraz pasków z gradientem stężenia antybiotyku. Wyniki oznaczeń lekowrażliwości interpretowano zgodnie z wytycznymi European Committee on Antimicrobial Susceptibility Testing (EUCAST), wersja 7.1. Analiza została wykonana retrospektywnie. Przedstawiono wyniki wrażliwości na penicylinę, ceftriakson, meropenem, wankomycynę, linezolid, rifampicynę, kotrimoksazol, lewofloksacynę oraz chloramfenikol. Część szczepów nie miała wykonanej lekowrażliwości na wszystkie przedstawione w pracy antybiotyki. W przypadku oznaczania wrażliwości na penicylinę i ceftriakson zawsze oznaczano MIC (Minimal Inhibitory Concentration), natomiast w przypadku pozostałych antybiotyków stosowano wymiennie metodę dyfuzyjno-krążkową lub gradient stężenia antybiotyku w pasku (bioMerieux, Liofilchem, Oxoid). W kontroli jakości stosowano szczep S. pneumoniae ATCC 49619. 


\section{STATISTICAL ANALYSIS}

To compare categorical variables between gender and etiological agent Chi-square distribution, Yates' correction for continuity or Fisher's exact test (depending on the size of the studied group) were used. The Kruskal-Wallis test with post-hoc analysis by Dunn Bonferroni test was used to evaluate the influence of patient's age on the etiological agents of meningitis.

\section{RESULTS}

During period of studies, 1303 CSF samples which were taken from 863 patients were analyzed, and 130 of them were positive. However, 29 samples were recognized as a contamination and rejected after analysis of analytic result and information in medical history. In group of 34 patients, the following bacterial genus were cultured: staphylococci, Gram-negative bacilli, enterococci, viridans group of streptococci and Actinomyces naeslundii which are not usually acknowledged as pathogen of meningitis. The analytical or preanalytical error could be the reason of the isolation of this species. Moreover, these cases were enrolled to the study after review of an analytic result of CSF, which indicated bacterial agent or did not exclude it when patient had additional clinical predisposition, like immunosuppression, anatomic defects of the skull and neurosurgery treatment. 101 strains, in total isolated from $101 \mathrm{CSF}$ sample which was taken from 96 patients were analyzed. Five patients had a recurrence within at least 2 month after they were cured their first BM and left the hospital. In three cases the next MB were caused by other etiological agent, whereas in two cases etiological agent was the same S. pneumoniae.

Etiological agents of BM isolated from CFS were shown in Fig. 1. The most frequent isolated organism is Streptococcus pneumoniae (36 strains), which consist $35.6 \%$ of all positive cases. Listeria monocytogenes is the second frequent etiological agent - $15.8 \%$ of all positive cases (16 strains). The next frequent are: Staphylococcus aureus - 12.9\% (13 strains), coagulase-negative staphylococci - 8.9\% (9 strains), Neisseria meningitidis - 5.9\% (6 strains), family Enterobacteriaceae - 5.9\% (6 strains), enterococci - 5.0\% (5 strains). Other streptococci species, like Streptococcus agalactiae, Streptococcus pyogenes, Streptococcus anginosus, Streptococcus equisimilis and Streptococcus mitis consist $5 \%$ of all isolates (5 strains). Moreover 4 strains of Acinetobacter baumanii are isolated (4\%), and one strain of Actinomyces naeslundii (1\%).

\section{STATYSTYKA}

Do oceny występowania zależności pomiędzy płcią pacjenta a stwierdzoną etiologią zapaleń opon mózgowo-rdzeniowych użyto testu $\chi 2$, testu $\chi 2$ z poprawką Yatesa lub dokładnym testem Fishera (w zależności od liczebności grup badanych). Do oceny, czy wiek wpływa na częstość występowania poszczególnych etiologii ZOMR użyto testu Kruskala-Wallisa $\mathrm{z}$ analizą post-hoc testem Dunn Bonferroni.

\section{WYNIKI}

W analizowanym czasie przebadano 1303 próbki PMR pobrane od 863 pacjentów, z których 130 było dodatnich. Jednakże po zapoznaniu się z wynikiem ogólnego badania PMR i informacjami zawartymi w karcie pacjenta, dane te zweryfikowano i 29 próbek PMR odrzucono, uznając jako pewne kontaminacje. U 34 pacjentów wyhodowano bakterie, które nie są powszechnie uznane za neuropatogeny u dorosłych, jak Staphylococcus aureus, gronkowce koagulazo-ujemne, Gram-ujemne pałeczki, enterokoki, paciorkowce z grupy viridans oraz Actinomyces naeslundii. Izolacja tych drobnoustrojów również może być skutkiem błędu przedlaboratoryjnego lub laboratoryjnego. Jednakże te przypadki zostały włączone do badania po analizie wyniku ogólnego badania PMR, który wskazywał na ropne ZOMR lub go nie wykluczał, przy współistnieniu dodatkowych obciążeń klinicznych pacjenta, takich jak obniżona odporność, wady anatomiczne czaszki lub wcześniejsze interwencje neurochirurgiczne. Ostatecznie analizie poddano 101 bakteryjnych szczepów wyizolowanych ze 101 próbek PMR, pobranych od 96 pacjentów. U pięciu pacjentów doszło do nawrotu w czasie co najmniej 2 miesięcy od wyleczenia i wypisania po pierwszym zachorowaniu. W trzech przypadkach kolejne zachorowanie wywołane było przez inny czynnik etiologiczny, a w dwóch czynnik etiologiczny był ten sam - S. pneumoniae.

Rycina 1 przedstawia czynniki etiologiczne BZOMR wyizolowane z posiewów PMR. Najwięcej, bo 35,6\% wszystkich dodatnich próbek zebranych w analizie stanowił Streptococcus pneumoniae (36 szczepów). Drugim pod względem częstości izolacji była Listeria monocytogenes (15,8 \%), którą wyizolowano w 16 przypadkach. Kolejnymi gatunkami były: Staphylococcus aureus - 12.9\% (13 szczepów), koagulazo-ujemne gronkowce $-8.9 \%$ (9 szczepów), Neisseria meningitidis $-5.9 \%$ (6 szczepów), pałeczki z rodziny Enterobacteriaceae - 5.9\% (6 szczepów), enterokoki - 5.0\% (5 szczepów). Pojedyncze przypadki innych niż pneumokoki paciorkowców, takich jak: Streptococcus agalactiae, Streptococcus pyogenes, Streptococcus anginosus, Streptococcus equisimilis oraz Streptococcus mitis stanowiły 5\% wszystkich izolatów (5 szczepów). Ponadto wyizolowano 4 szczepy pałeczek Acinetobacter baumannii (4\%) oraz jeden Actinomyces naeslundii (1\%). 


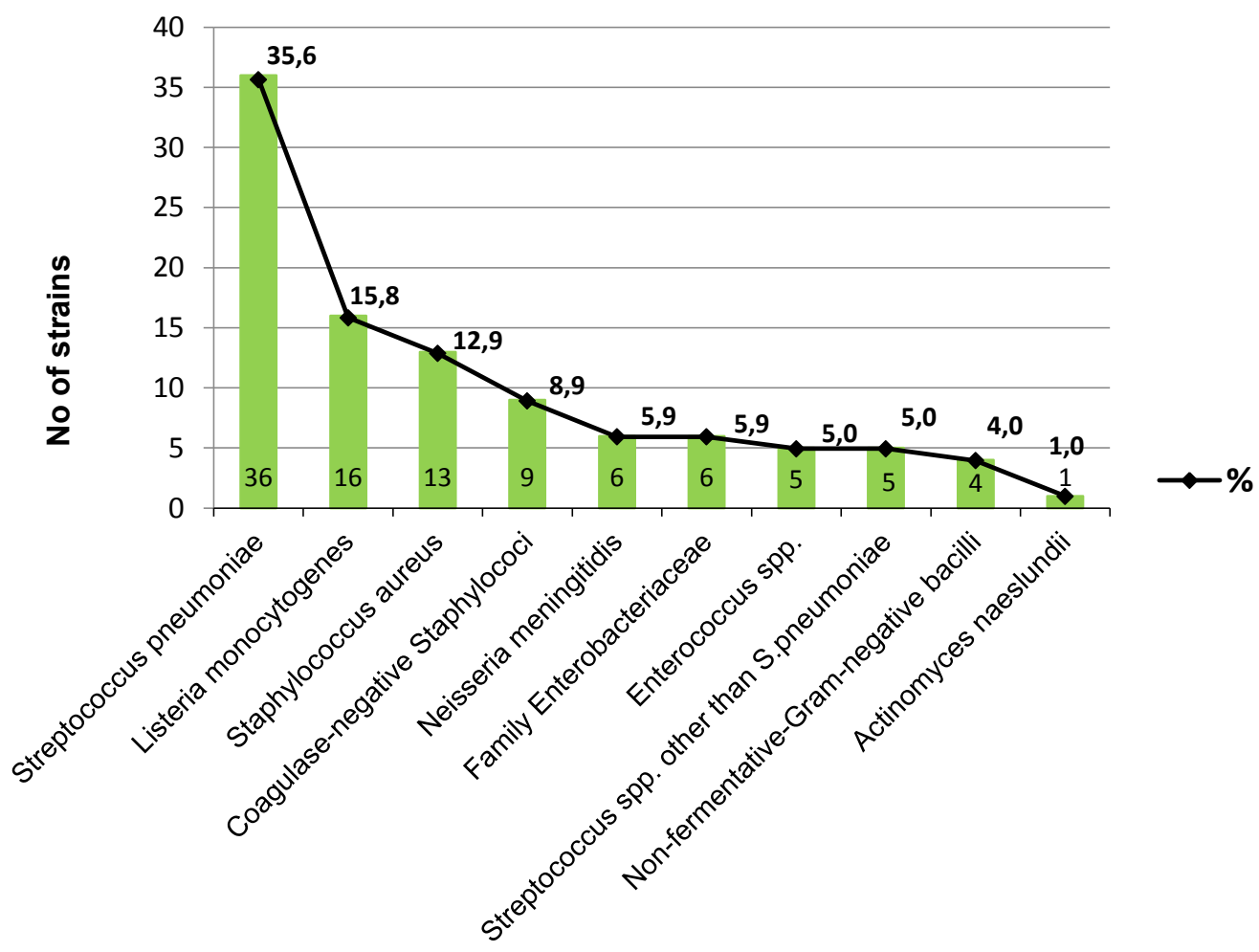

Fig. 1. Etiological agents of BM isolated between 2009-2016 (n=101).

Ryc. 1. Czynniki etiologiczne BZOMR wyizolowane w latach 2009-2016 ( $\mathrm{n}=101)$.

Patients in age over 18 years were enrolled to this study, however the youngest patient with confirmed $\mathrm{BM}$ was 20 years old. The range of patients' age with confirmed bacterial meningitis is 20-89 years old and the median age is 53. Examinated group consist of 43 women (mean age: 56 years old) and 58 men (mean age: 51 years old). Any significant relationship between patient gender and etiological agents of meningitis was not indicated.

The most prevalent in this study speciesStreptococcus pneumoniae was isolated from patients in age between 22-66 years old, while median age of this group was 52. Listeria monocytogenes was cultured from patients between 31 and 81 years old, which median age is 57 . From two of the oldest patients' groups Staphylococcus aureus (median age 67 years old) and Gram-negative, nonfermentative bacilli- Acinetobacter baumannii (median age 69 years old) were isolated. Neisseria meningitidis was isolated from the youngest patients group, despite that the range of age was 20-61 years, but median age was 37 . The study shows that patients infected with Neisseria meningitides were younger than those infected with Staphylococus aureus $(\mathrm{p}=0.04)$ and Gram-negative bacilli (Enterobacteriaceae and non-fermentative $)(\mathrm{p}=0.03)$. Any other significant differentiation between etiology and age was not found. Among patients group between 20-50 years in total 37 bacterial strains were isolated and 16 of them was Streptococcus pneumoniae, which consists $43 \%$.
Analiza obejmowała pacjentów od 18 roku życia, jednak najmłodszy pacjent $\mathrm{z}$ potwierdzonym ropnym ZOMR miał lat 20. Zakres wiekowy grupy badanej to 20-89 lat, a średnia wieku wyniosła 53 lata. Grupa badana składa się z 43 kobiet (średnia wieku 56 lat) oraz 58 mężczyzn (średnia wieku 51 lat). Nie stwierdzono istotnie statystycznych różnic w częstości występowania poszczególnych etiologii ZOMR w zależności od płci.

Najczęstszy w badaniu neuropatogen - Streptococcus pneumoniae, był izolowany od pacjentów w wieku od 22-66 lat, natomiast średnia wieku w tej grupie to 52 lata. Listeria monocytogenes wyhodowano od pacjentów pomiędzy 32 a 81 rokiem życia, których średnia wieku wyniosła 57 lat. Od dwóch najstarszych grup pacjentów wyizolowano Staphylococcus aureus (średnia wieku 67 lat) oraz Gram-ujemne pałeczki niefermentujące Acinetobacter baumannii (średnia wieku 69 lat). Neisseria meningitidis izolowano od najmłodszej grupy pacjentów i choć zakres wiekowy obejmował od 20-61 lat, to średnia ich wieku wyniosła 37 lat. Wykazano, iż pacjenci zakażeni Neisseria meningitidis byli młodsi zarówno od grupy z etiologią Staphylococcus aureus $(\mathrm{p}=0,04)$, jak i pałeczkami Gram-ujemnymi (jelitowymi oraz niefermentującymi) $(p=0,03)$. Innych statystycznie istotnych różnic w etiologii ZOMR w zależności od wieku pacjentów nie stwierdzono. W grupie wiekowej 20-50 lat wyhodowano 37 szczepów, z czego $43 \%$ stanowiło 16 przypadków izolacji Streptococcus pneumoniae. Drugie pod względem czę- 
The second frequent etiological agents were: Listeria monocytogenes $(13.5 \%)$ and coagulase-negative staphylococci $(13.5 \%)$. Occasionally were isolated Neisseria meningitides (8\%), other than Streptococcus pneumoniae streptococci (8\%), and Staphylococcus aureus (8\%). The cultures of other species were rare. Among patients $>50$ years old also the most frequent isolated microorganism was Streptococcus pneumoniae, which consist $31.3 \%$ (20 strains), and the second frequent was Listeria monocytogenes (17.2\%). In patients group $>50$ years old 10 cases were caused by Staphylococcus aureus, which consist 15.3\% of all strains in this group. Moreover, all strains of entrobacteria were cultured from patients $>50$ years old. More details were shown in Tab I. stości izolacji były pałeczki Listeria monocytogenes $(13,5 \%)$ oraz gronkowce koagulazo-ujemne $(13,5 \%)$. Rzadziej izolowano Neisseria meningitidis (8\%), inne niż pneumokoki paciorkowce (8\%), oraz Staphylococcus aureus (8\%). Hodowle pozostałych gatunków były sporadycznie. W grupie wiekowej $>50$ roku życia również najczęściej izolowano Streptococcus pneumoniae, który stanowił 31,3\% izolatów (20 szczepów), a drugim pod względem częstości izolacji była Listeria monocytogenes $(17,2 \%)$. U pacjentów $>50$ lat zanotowano 10 przypadków wywołanych przez gronkowca złocistego, co stanowi 15,3\% wszystkich izolacji w tej grupie wiekowej. Ponadto wszystkie szczepy pałeczek jelitowych pochodziły od pacjentów $>50$ roku życia. Szczegółowe dane przedstawiono w tabeli I.

Table I. Patients median age and number of isolated strains according to etiology of BM.

Tabela I. Mediana wieku pacjentów o danej etiologii BZOMR oraz liczba wyhodowanych szczepów.

\begin{tabular}{|c|c|c|c|c|}
\hline \multirow{2}{*}{ Etiological agent } & \multirow{2}{*}{ Median age } & \multicolumn{2}{|c|}{$\begin{array}{c}\text { Patients age group } \\
\text { number of isolates }(\%)\end{array}$} & \multirow{2}{*}{$\begin{array}{c}\text { All patients } \\
(\%)\end{array}$} \\
\hline & & 20 - 50 years old & $>50$ years old & \\
\hline Streptococcus pneumoniae & 52 & $16(43 \%)$ & $20(31.3 \%)$ & $36(35.6 \%)$ \\
\hline Listeria monocytogenes & 57 & $5(14 \%)$ & $11(17.2 \%)$ & $16(15.8 \%)$ \\
\hline Neisseria meningitidis & 37 & $3(8 \%)$ & $3(4.7 \%)$ & $6(5.9 \%)$ \\
\hline Staphylococcus aureus & 67 & $3(8 \%)$ & $10(15.6 \%)$ & $13(12.9 \%)$ \\
\hline Coagulase-negative staphylococci & 45 & $5(14 \%)$ & $4(6.3 \%)$ & $9(8.9 \%)$ \\
\hline Other streptococci & 47 & $3(8 \%)$ & $2(3.1 \%)$ & $5(5 \%)$ \\
\hline Enterococcus spp. & 54 & $1(3 \%)$ & $4(6.3 \%)$ & $5(5 \%)$ \\
\hline Family Enterobacteriaceae & 64 & 0 & $6(9.4 \%)$ & $6(5.9 \%)$ \\
\hline Acinetobacter baumannii & 69 & $1(3 \%)$ & $3(4.7 \%)$ & $4(4 \%)$ \\
\hline Actinomyces naeslundii & 67 & 0 & $1(1.6 \%)$ & $1(1 \%)$ \\
\hline Total & 53 & 37 & 64 & 101 \\
\hline
\end{tabular}

\section{Antibiotic susceptibility}

All strains of Neisseria meningitidis were sensitive to penicillin and ceftriaxone. Detailed analysis of antimicrobial susceptibility was performed to the most frequent organism isolated from CSF - Streptococcus pneumoniae. Antimicrobial susceptibility of 36 Streptococcus pneumoniae strains to 9 antimicrobial drugs was shown in Fig. 2.

All tested strains were sensitive to vancomycin $(\mathrm{n}=36)$, linezolid $(\mathrm{n}=13)$, rifampicin $(\mathrm{n}=8)$, levofloxacin $(n=7)$ and chloramphenicol $(n=5)$. One strain was intermediately sensitive to ceftriaxone $(2.8 \% ; \mathrm{n}=36)$, another one to meropenem $(3.6 \% ; n=28)$ and to cotrimoxazol $(5.3 \% \mathrm{n}=19)$. Resistance to penicillin was determined in $27.8 \%$ of tested strains $(\mathrm{n}=36)$, and $21 \%$ were resistant to co-trimoxazol $(\mathrm{n}=19)$.

\section{Lekowrażliwość}

Wszystkie szczepy Neisseria meningitidis wykazywały pełną wrażliwość na penicylinę i ceftriakson. Szczegółową analizę lekowrażliwości wykonano dla najczęściej izolowanego patogenu - Streptococcus pneumoniae. Profil lekowrażliwości 36 wyhodowanych szczepów wobec 9 antybiotyków i chemioterapeutyków rozważanych w terapii ZOMR przedstawia rycina 2.

Wszystkie badane szczepy $S$. pneumoniae charakteryzowały się wrażliwością na wankomycynę $(n=36)$, linezolid $(n=13)$, rifampicynę $(n=8)$, lewofloksacynę $(n=7)$ oraz chloramfenikol $(n=5)$. Jeden raz odnotowano średnią wrażliwość wobec ceftriaksonu $(2,8 \%$; $n=36)$, meropenemu $(3,6 \% ; n=28)$ oraz kotrimoksazolu $(5,3 \% \mathrm{n}=19)$. Oporność na penicylinę wykazywało $27,8 \%$ szczepów ( $\mathrm{n}=36)$, a $21 \%$ było opornych na kotrimoksazol $(\mathrm{n}=19)$. 


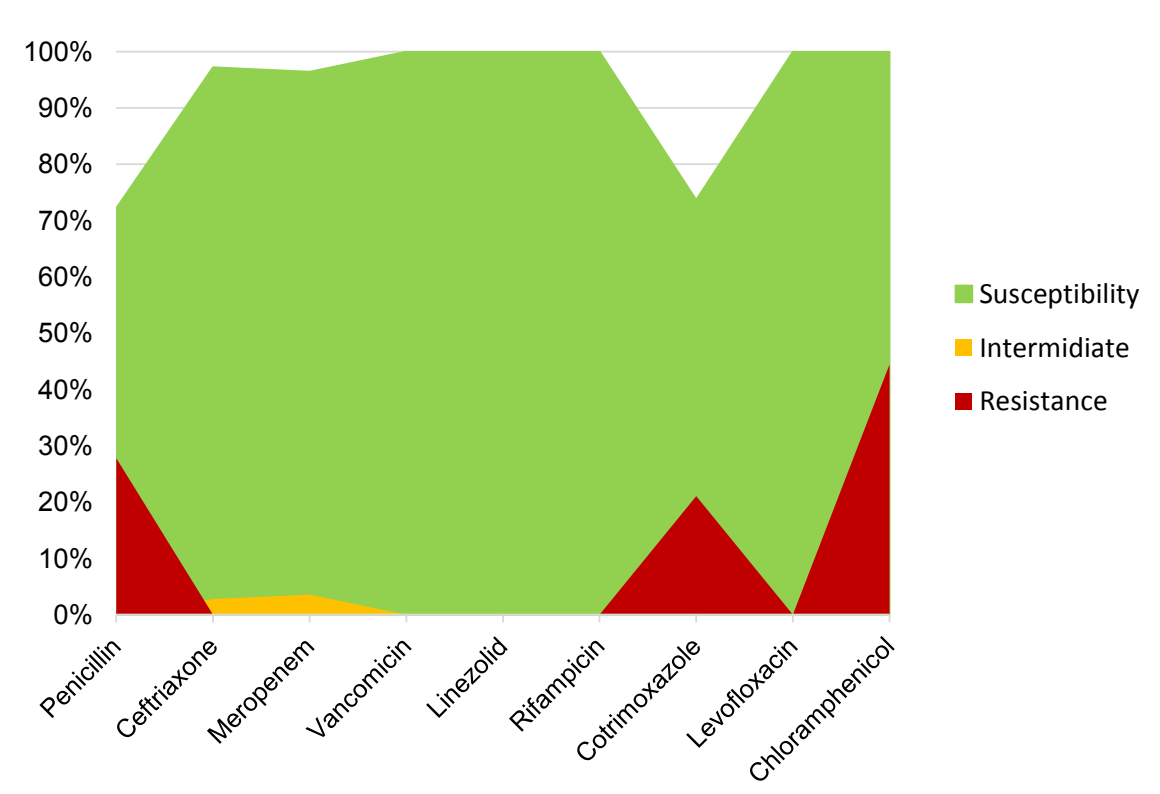

Fig. 2. Antimicrobial susceptibility of S. pneumoniae strains isolated from CSF between 2009-2016. Ryc. 2. Lekowrażliwość S. pneumoniae wyizolowanych z PMR w latach: 2009-2016.

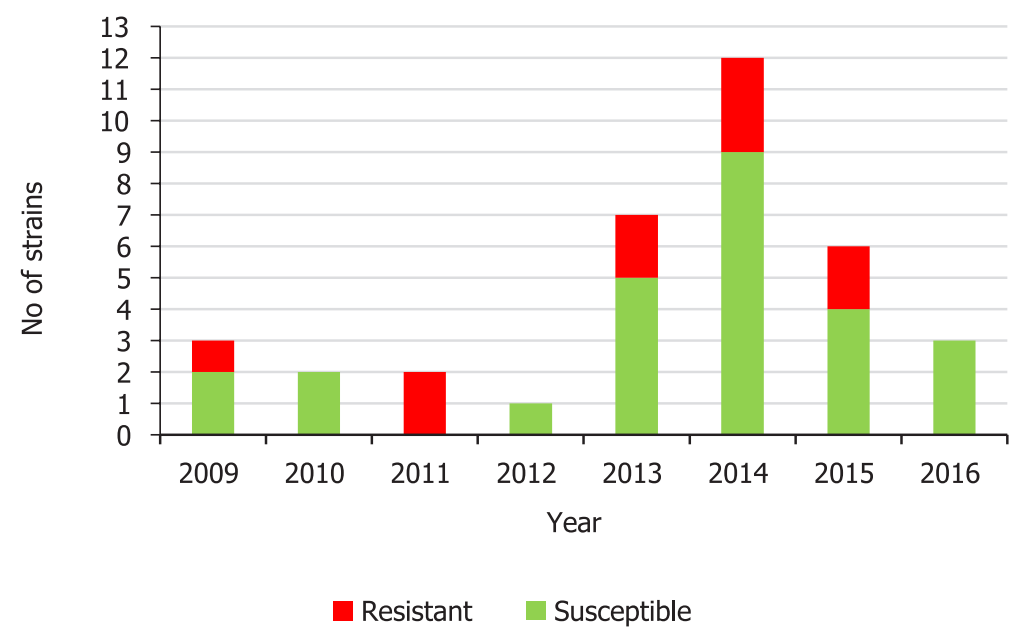

Fig. 3. Number of S.pneumoniae isolates susceptible and resistant to penicillin, 2009-2016.

Ryc. 3. Liczba szczepów S.pneumoniae wrażliwych oraz opornych na penicylinę w latach 2009-2016.

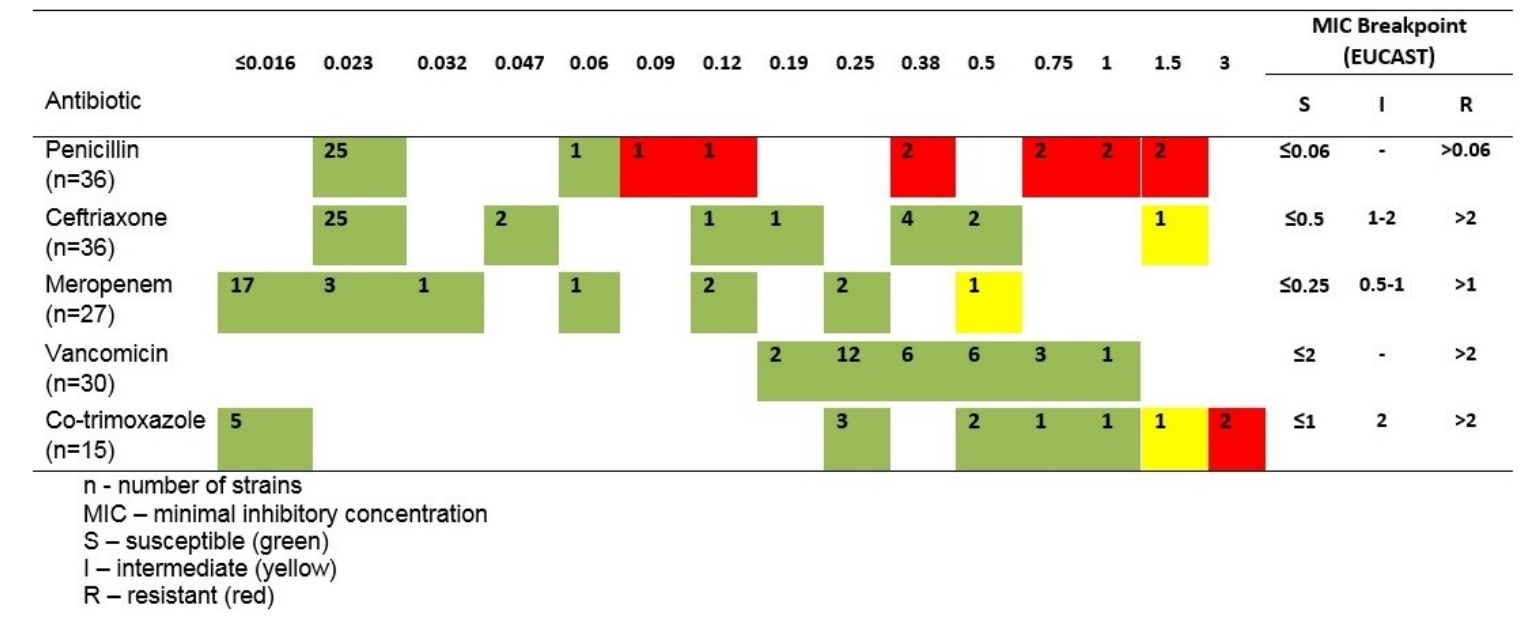

Table II. Distribution of penicillin, ceftriaxone, meropenem, vancomycin and co-trimoksazole MIC value of invasive S. pneumoniae strains.

Tabela II. Rozkład wartości MIC penicyliny, ceftriaksonu, meropenemu, wankomycyny oraz kotrimoksazolu szczepów S. pneumoniae. 
Between 2009-2016 any significant differences of susceptibility to penicillin were not observed (Fig. 3.) Only one strain which was isolated in 2009 was intermediately susceptible to ceftriaxone, whereas rest of 35 strains were classified as susceptible.

MIC value distribution of antibiotic analyzed in this study was shown in Table II. The highest MIC value of penicillin $(1.5 \mathrm{mg} / \mathrm{L})$ revealed two strains. The most prevalent was the lowest penicillin MIC value $\leq 0.023 \mathrm{mg} / \mathrm{L}$ which was demonstrated by 25 tested strains $(69.4 \%)$. The lowest MIC value of ceftriaxone $\leq 0.023 \mathrm{mg} / \mathrm{L}$ was observed in $69.4 \%$ of all strains. Among all of 27 tested pneumococci, 17 strains (63\%) had the lowest MIC value of meropenem, which accounted $\leq 0.01 \mathrm{mg} / \mathrm{L}$. One strain from 2009 had $\mathrm{MIC}=0.5 \mathrm{mg} / \mathrm{L}$ and it was specified as intermediately susceptible to meropenem. Resistance to meropenem was not observed. All pneumococci strains were sensitive to vancomycin and $40 \%$ of them (12 strains) had $\mathrm{MIC}=0.25 \mathrm{mg} / \mathrm{L}$. However one strain from 2013 had elevated value of $\mathrm{MIC}=1 \mathrm{mg} / \mathrm{L}$. Most strains were susceptible to co-trimoxazole, and 5 among 15 strains had the lowest MIC $\leq 0.1 \mathrm{mg} / \mathrm{L}$. However, two strains which were isolated in 2009 and 2011 were resistant $(\mathrm{MIC}=3 \mathrm{mg} / \mathrm{L})$ and one, isolated in 2016 was intermediately susceptible (MIC $=1.5 \mathrm{mg} / \mathrm{L}$ ) to this drug.

The incidence of bacterial meningitis varies throughout the world. In the UK and Western Europe, the incidence is $1-2$ cases per 100000 people per year, whereas it can reach 1000 cases per 100000 people per year in the Sahel region of Africa (1). The annual incidence of bacterial meningitis in Poland in 2016 was reported as 2.43 per 100000 population (2). Streptococcus pneumoniae is pointed as the most frequent etiological agent of BM. These Gram-positive diplococci, named as "captain of death" are responsible for most meningitis cases, what was also proved in this study (1), (3). In Poland vaccination against pneumococci as a part of the routine immunization schedule has been introduced in 2017. Earlier this vaccine was only recommended but founded only for high-risk groups of invasive pneumococcal disease. Specially predicted to meningitis caused by Streptococcus pneumoniae are patients with underlying conditions such as splenectomy, multiple myeloma, hypogammaglobulinemia, alcoholism, chronic liver or kidney disease, malignancy, Wiskott-Aldrich syndrome, diabetes mellitus. BM caused by Streptococcus pneumoniae is observed mainly in patients groups at the extremes of age $(<2$ and $>50$ years old). However, in this study was not observed any difference in prevalence of pneumococci in patients group $20-50$ years old and $>50$ (39\% of all isolated strains vs. $31 \%$ ) and the mean age of all patients in this study was only 54 . Neisseria meningitidis
W latach 2009-2016 nie zaobserwowano znaczących zmian w lekowrażliwości wyizolowanych z PMR szczepów Streptococcus pneumoniae na penicylinę, co przedstawia Ryc. 3. Tylko jeden szczep wyizolowany w 2009 roku wykazywał średnią wrażliwość na ceftriakson, natomiast 35 pozostałych szczepów sklasyfikowano jaki wrażliwe.

Tabela nr II przedstawia rozkład wartości MIC analizowanych w pracy antybiotyków. Najwyższą wartość MIC dla penicyliny $(1.5 \mathrm{mg} / \mathrm{L})$ wykazywały 2 szczepy. Najwięcej, bo 25 szczepów $(69,4 \%)$ cechowała niska wartość MIC penicyliny $\leq 0.023 \mathrm{mg} / \mathrm{L}$. Najniższą wartość MIC ceftriaksonu $\leq 0.023 \mathrm{mg} / \mathrm{L}$ uzyskano dla 69,4\% szczepów. Spośród 27 badanych szczepów 17 charakteryzowała wysoka wrażliwość wobec meropenemu MIC $\leq 0.01 \mathrm{mg} / \mathrm{L}(63 \%)$. Jeden szczep pochodzący z 2009 roku wykazywał średnią wrażliwość (MIC= $0.5 \mathrm{mg} / \mathrm{L}$ ) wobec tego antybiotyku. Nie zaobserwowano oporności na meropenem. Wszystkie pneumokoki charakteryzowała wrażliwość na wankomycynę, a u $40 \%$ z nich ( 12 szczepów) odnotowano $\mathrm{MIC}=0.25$ $\mathrm{mg} / \mathrm{L}$. Jednakże jeden szczep w 2013 roku wykazywał podwyższoną wartość MIC=1 mg/L. Większość szczepów cechowała wrażliwość na kotrimoksazol, a 5 spośród 15 wykazywało MIC $\leq 0.1 \mathrm{mg} / \mathrm{L}$. Jednakże dwa szczepy pochodzące $z$ lat 2009 oraz 2011 były oporne (MIC $=3 \mathrm{mg} / \mathrm{L}$ ), a jeden z 2016 roku średniowrażliwy $(\mathrm{MIC}=1.5 \mathrm{mg} / \mathrm{L})$.

Zapadalność na ropne ZOMR różni się w poszczególnych częściach świata. W Wielkiej Brytanii i Europie zachodniej rocznie notuje się 1-2 przypadki/ 100000 ludności, podczas gdy w regionie subsaharyjskim Afryki liczba ta może osiągać nawet 1000 przypadków/ 100000 osób (1). W Polsce wartość ta w 2016 roku oszacowana została na 2,43/ 100000 osób (2). Jako najczęstszy czynnik wywołujący ZOMR wskazywany jest Streptococcus pneumoniae (1), (3) określany jako "kapitan śmierci", co również znalazło potwierdzenie $\mathrm{w}$ prezentowanej pracy. W Polsce szczepienia przeciw pneumokokom zostały wprowadzone do obowiązkowego kalendarza szczepień w 2017 roku, a w latach wcześniejszych były jedynie zalecane, a refundowane dla grupy podwyższonego ryzyka. Szczególnie narażone są osoby po splenektomii, z hipergammaglobulinemią, szpiczakiem mnogim, przewlekłymi chorobami wątroby i nerek, z nowotworami złośliwymi, zespołem Wiskotta-Aldricha, cukrzycą oraz alkoholicy. ZOMR wywołane przez pneumokoki najczęściej występuje u osób w skrajnych grupach wiekowych - poniżej 2 oraz powyżej 50 roku życia. Jednakże w prezentowanym badaniu nie zanotowano znaczącej różnicy w częstości izolacji Streptococcus pneumoniae od pacjentów $>50$ lat $(39 \%)$ w porównaniu do grupy wiekowej 18-50 lat (31\%), a średnia wieku chorych o tej etiologii wyniosła 54 lata. 
is described to be the second frequent agent of BM, but in this study was isolated only 6 times. The reason of such low number of this etiology could be prelaboratory or laboratory errors, which could appeared during transport of CSF sample. Temperature $<36^{\circ} \mathrm{C}$ could reduce the vitality of bacterial cells. Probably, part of cases with unidentified etiology could be caused by meningococci. The hospital has its own laboratory with 24 hours access to microbiological diagnostic, where the samples are always immediately prepared. However, laboratory and medical wards are located in separated buildings and the medical samples are transported in isolated boxes. Despite proper attention, this moment could be critical and may need more analyze.

Nowadays, there are available vaccines against all most frequent serotypes, but in Poland the refund includes only population with a medical conditions that increase their risk of the disease. Beyond this group meningococcal vaccination is offered as an additional and private founded. Meningococci are the most common cause of bacterial meningitis in children and young adults (6). Our findings are consistent with this knowledge, because patients infected with this bacteria were the youngest group, with median age of 37. Despite such low number of strains, this etiological agent was isolated tree-times more frequently in patients group $\leq 50$ years than in the older patients group (consists $9.8 \%$ ver. $3.1 \%$ of all isolated strains). Patients infected with Neisseria meningitidis were younger than those with etiology of Staphylococcus aureus $(\mathrm{p}=0,04)$ and Gram-negative bacilli $(\mathrm{p}=0.03)$.

Due to implementation of universal vaccination, an incidence of Haemophilus influenzae meningitis in Europe is very low (5). In Poland in 2016 it was assessed at 0.02 per 100000 population (2). Morever, Haemophilus influenzae infect mainly children. For that reason, do not surprise the fact, that in our study did not detect any case of Haemophilus influenzae isolation.

Due to still increasing population of immunocompromised and elderly persons in Europe was observed an increased incidence caused by other species, like Listeria monocytogenes (6). It was the second frequent isolated bacteria in this study, which consist $15.2 \%$ of all cases and median age of infected patients was 57 years. Actually this etiology among adults may consist $4 \%-16.5 \%$ of cases (7).

We noticed, that Gram-negative bacilli and Staphylococcus aureus were isolated from the oldest patients group, with median age: 69 and 67, (vs. median age of all patients: 53). All strains of Gram-negative bacilli were isolated from patients $>50$ years old. It is interesting, that such controversial agent of bacterial meningitis, like coagulase-negative staphylococci $(n=9)$ was most often detected in younger persons with
Neisseria meningitidis jest określana jako drugi najczęstszy czynnik ZOMR, jednak w przedstawionej pracy była izolowana tylko w 6 przypadkach. Być może powodem tak małej liczby uzyskanych hodowli jest wystąpienie błędów przedlaboratoryjnych lub laboratoryjnych, powstałych wskutek obniżenia temperatury transportu próbki poniżej $36^{\circ} \mathrm{C}$, co mogło drastycznie obniżyć żywotność komórek bakteryjnych. Możliwe, że część przypadków, w których nie udało się ustalić etiologii, wywołanych było właśnie przez meningokoki. Szpital posiada własne laboratorium z całodobowym dostępem do diagnostyki mikrobiologicznej, w którym próbki są zawsze niezwłocznie opracowywane. Jednakże zarówno laboratorium, jak i poszczególne oddziały usytuowane są w odrębnych budynkach, a próbki przenoszone są w izolowanym pojemniku termicznym. Być może pomimo wszelkich starań, to jest ten krytyczny etap, któremu należałoby się bliżej przyjrzeć.

Obecnie dostępne są szczepionki przeciwko większości wywołujących ZOMR serotypów Neisseria meningitidis, jednak w Polsce refundowane są tylko dla osób z grup podwyższonego ryzyka inwazyjnej choroby meningokokowej. Dwoinki te najczęściej zakażają dzieci i młodych dorosłych (4), co znalazło potwierdzenie $\mathrm{w}$ prezentowanej pracy przedstawiającej chorych o tej etiologii, jako najmłodszą grupę pacjentów o średniej wieku 37 lat. Pomimo małej liczby wyhodowanych szczepów, meningokoki były 3 razy częściej izolowane $w$ grupie wiekowej $\leq 50$ lat niż u pacjentów starszych $(9,8 \%$ vs. $3,1 \%$ wszystkich wyhodowanych szczepów). Pacjenci zakażeni Neisseria meningitidis byli statystycznie młodsi od grupy pacjentów z etiologią Staphylococcus aureus $(\mathrm{p}=0,04)$ oraz pałeczkami Gram-ujemnymi $(\mathrm{p}=0,03)$.

Wprowadzenie w Europie powszechnych szczepień przeciw Haemophilus influenzae typu B radykalnie zmniejszyło liczbę przypadków ZOMR o tej etiologii (5). W Polsce w 2016 roku zapadalność oszacowano na 0,02/100 000 osób (2). Ponadto drobnoustrój ten wywołuje infekcje u dzieci. Dlatego brak wystąpienia przypadków Haemophilus influenzae w tej pracy nie jest zaskakujący.

W Europie na skutek starzenia się społeczeństwa i zwiększającej się grupy osób o obniżonej odporności obserwuje się wzrost zachorowań wywołanych przez inne drobnoustroje, jak np. Listeria monocytogenes (6). W prezentowanej pracy był to drugi pod względem częstości izolacji czynnik etiologiczny, stanowiący $15,2 \%$ przypadków, ze średnią wieku pacjentów, równą 57 lat. Szacuje się, że obecnie wśród dorosłych może wywoływać od $4 \%-16,5 \%$ przypadków bakteryjnego ZOMR (7).

W badaniu tym zaobserwowano, że Gram-ujemne pałeczki oraz Staphylococcus aureus wywoływa- 
median age: 45 . This phenomenon could be caused by the contamination of patients saprophytic flora (prelaboratory errors) or laboratory stuff (laboratory errors) and the real pathogen could be different. However, those cases were included to the study, due to diagnosis and the result of analytical examination, which did not exclude bacterial etiology. Other causes of meningitis, like bacilli from Enterobacteriaceae family $(n=6)$, enterococci $(n=5)$, streptococci $(n=5)$, and Gram-negative non-fermentative bacilli $(\mathrm{n}=4)$ were detected in several cases. According to previous studies these agents are rare and occurs in patients with risk factors such as older adults, alcoholics, diabetics, patients with malignancies and immunocompromised (1).

In patients group $>50$ years old the most frequent bacterialetiologicagentsofmeningitisareStreptococcus pneumoniae, Listeria monocytogenes, Staphylococcus aureus. However, almost $36 \%$ of strains belongs to rarely noticed species, like Escherichia coli $(\mathrm{n}=4)$, Klebsiella pneumoniae $(\mathrm{n}=2)$, coagulase-negative staphylococci $(\mathrm{n}=4)$, enterococci $(\mathrm{n}=4)$, Acinetobacter baumannii $(\mathrm{n}=3)$, Streptococcus pyogenes $(\mathrm{n}=1)$, Streptococcus anginosus $(\mathrm{n}=1)$. Coexisting of additional conditions and immunocompromised is associated with appearance of these species, which is consistent with other studies (8), (4).

Resistance to penicillin was observed in $27.8 \%$ of strains ( $\mathrm{n}=10)$, and MIC was range: $0.094-1.5 \mathrm{mg} / \mathrm{L}$. A similar proportion of strains resistant to penicillin - 24.8\% was presented in the BINet study from 20112013 (9). According to a report of the European Antimicrobial Resistance Surveillance Network (EARS-Net) from 2015 the percentage of strains not susceptible to penicillin ranged from $0.6 \%$ (Belgium) to $39.0 \%$ (Romania). However, it should be noted that in those study, strains were isolated from different forms of invasive infections, not only from meningitis. According to this report in Poland $24.4 \%$ of strains were described as not susceptible to penicillin, while in neighboring countries this percentage ranged from $22 \%$ in Slovakia, $16.8 \%$ in Lithuania, $8.5 \%$ in Latvia, $6.8 \%$ in Sweden and $6.1 \%$ in Germany to $3.2 \%$ in the Czech Republic (10). Unfortunately, in other parts of the world the sensitivity of $S$. pneumoniae to penicillin is much lower. In Nigeria, only $16.7 \%$ of invasive strains had $\mathrm{MIC} \leq 0.06 \mathrm{mg} / \mathrm{L}$ (11).

Reduced susceptibility to ceftriaxone (MIC > $0.5 \mathrm{mg} / \mathrm{L})$ was observed in one case $(2.8 \%)$ in this study, while according to the BINet report, reduced susceptibility to other third-generation cephalosporinscefotaxime was reported in 10\% of all invasive strains (9). Similar level to presented in this study of reduced sensitivity to this group of antibiotics was described in Switzerland, where $2.2 \%$ of invasive pneumococi ły ZOMR u najstarszych pacjentów, których średnia wieku wynosiła odpowiednio: 69 oraz 67 lat (vs. średnia wieku wszystkich pacjentów: 53 lata). Wszystkie szczepy pałeczek jelitowych były izolowane od pacjentów $>50$ roku życia. Co ciekawe, tak kontrowersyjny czynnik bakteryjnego ZOMR, jak gronkowce koagulazo-ujemne $(\mathrm{n}=9)$ występowały u pacjentów znacznie młodszych, których średnią wieku określono na 45 lat. Zjawisko to może mieć związek z kontaminacją próbki saprofityczną florą skóry pacjenta (błąd przedlaboratoryjny) lub personelu laboratoryjnego (błąd laboratoryjny), a rzeczywisty drobnoustrój wywołujący infekcję może być zupełnie inny. Jednak z uwagi na postawione rozpoznanie kliniczne oraz wynik badania ogólnego PMR, który nie wykluczał bakteryjnej etiologii, przypadki te zostały włączone do analizy. Pałeczki jelitowe $(n=6)$, enterokoki $(n=5)$, paciorkowce $(n=5)$, czy niefermentujące pałeczki Gram-ujemne $(n=4)$, były izolowane sporadycznie, a ich pojawianie się jako czynników ZOMR wiązane jest z obniżeniem odporności pacjentów wskutek zaawansowanego wieku, cukrzycy, alkoholizmu lub choroby nowotworowej (1).

W grupie wiekowej $>50$ roku życia najczęstszym czynnikiem etiologicznym bakteryjnego ZOMR były: Streptococcus pneumoniae, Listeria monocytogenes, Staphylococcus aureus. Jednakże prawie 36\% szczepów należało do innych gatunków, izolowanych sporadycznie, jak: Escherichia coli $(\mathrm{n}=4)$, Klebsiella pneumoniae $(\mathrm{n}=2)$, gronkowce koagulazo-ujemne $(\mathrm{n}=$ 4), enterokoki ( $\mathrm{n}=4)$, Acinetobacter baumannii $(\mathrm{n}=3)$, Streptococcus pyogenes $(\mathrm{n}=1)$, Streptococcus anginosus $(\mathrm{n}=1)$. Na pojawieniesię takich czynników ma wpływ współistnienie dodatkowych chorób i obciążeń, co znajduje potwierdzenie w literaturze (8), (4).

Oporność na penicylinę wykazywało $27,8 \%$ badanych szczepów $(n=10)$, a ich zakres wartości MIC to $0,094-1,5 \mathrm{mg} / \mathrm{L}$. Podobny odsetek szczepów opornych na penicylinę, wynoszący $24,8 \%$ przedstawiono w badaniu BINet z lat 2011-2013 (9). Według raportu European Antimicrobial Resistance Surveillance Network (EARS-Net) z 2015 roku procent szczepów niewrażliwych na penicylinę wahała się od $0,6 \%$ (Belgia) do 39,0\% (Rumunia). Należy podkreślić, że przedstawione w tym opracowaniu szczepy pochodziły z różnych postaci zakażeń inwazyjnych, nie tylko z ZOMR. Według tego raportu w Polsce $24,4 \%$ szczepów opisano jako niewrażliwe na penicylinę, podczas gdy w sąsiednich krajach odsetek ten wynosił od $22 \%$ na Słowacji, 16,8\% na Litwie, 8,5\% na Łotwie, 6,8 \% w Szwecji i 6,1\% w Niemczech do 3,2\% w Czechach (10). Niestety w innych częściach świata wrażliwość Streptococcus pneumoniae na penicylinę jest znacznie niższa. W Nigerii tylko 16,7\% szczepów z zakażeń inwazyjnych wykazywała MIC $\leq 0.06 \mathrm{mg} / \mathrm{L}$ (11). 
strains showed reduced sensitivity (12). Also in Nigeria, ceftriaxone shows good activity against local strains, where $3.8 \%$ of strains are characterized as resistant (11), while according to the global research carried out between 2004-2013, the resistance of invasive and non-invasive strains of $S$. pneumoniae was assessed to $1.2 \%$ (13).

Reduced susceptibility to meropenem (MIC $>0.25$ $\mathrm{mg} / \mathrm{ml}$ ) was obtained in one case (MIC $=0.5 \mathrm{mg} / \mathrm{L}$ ), it represents $3.7 \%$ of all strains. This percentage is similar to BiNet report (5\%) (9), but much lower than $10 \%$ of resistance, which was presented in the global analysis including invasive and non-invasive strains (13).

All strains showed susceptibility to vancomycin, which is consistent with other observations (14), (13). Non susceptibility to co-trimoxasole was observed in $26.3 \%$ cases. In the Swiss study $14.4 \%$ of invasive strains isolated between the 2004-2014 from patients in age: 5-64 years old were resistant to co-trimoxazole (MIC $\geq 4 \mathrm{mg} / \mathrm{ml}$ ) (12). High percentage of resistance is noticed in Africa, especially among patients infected with HIV, who receive co-trimoxazole in the prevention of opportunistic infections. In this group $84 \%$ of invasive strains of $S$. pneumoniae are resistant to this drug (15).

\section{CONCLUSION}

S. pneumoniae was the most common etiological agent $(36.5 \%)$ of $\mathrm{BM}$ in both patient age groups: adults aged $>50$ years and adults aged 20-50 years. N.meningitidis was isolated most frequent from patients $\leq 50$ years, while $S$. aureus and Gram-negative bacilli were obtained mainly from group $>50$ years old. All tested strains of S.pneumoniae were sensitive to vancomycin, linezolid, levofloxacin, rifampicin and chloramphenicol. High percentage of full sensitivity to ceftriakson (97.2\%) and meropenem (96.4\%) was observed. Resistance to penicillin was detected in $27.8 \%$ of all strains.

\section{REFERENCES}

1. McGill F, Heyderman RS, Panagiotou S, et al. Acute bacterial meningitis in adults. The Lancet 2016;288, 10063:3036-3047.

2. NIZP-PZH Zakład Epidemiologii i GIS Departament Zapobiegania oraz Zwalczania Zakażeń i Chorób Zakaźnych u Ludzi. Zachorowania na wybrane choroby zakaźne w Polsce od 1 stycznia do 31 grudnia 2016 r. oraz $\mathrm{w}$ porównywalnym okresie $2015 \mathrm{r}$.

3. Bareja R, Pottathil S, Shah RK, et al.Trends in Bacterial etiology amongst cases of Meningitis. J.
Obniżoną wrażliwość na ceftriakson (MIC $>0.5$ $\mathrm{mg} / \mathrm{L}$ ) w prezentowanym badaniu zaobserwowano w jednym przypadku $(2,8 \%)$, podczas gdy według raportu BINet wobec innej cefalosporyny III generacjicefotaksymu odsetek ten wynosił $10 \%$ spośród wszystkich szczepów inwazyjnych (9). Podobny do odnotowanego w tym badaniu poziom obniżonej wrażliwości na tą grupę antybiotyków opisano w Szwajcarii, gdzie 2,2\% pneumokoków z zakażeń inwazyjnych wykazywało obniżoną wrażliwość (12). Również w Nigerii ceftriakson wykazuje doskonałą aktywność wobec tamtejszych szczepów z 3,8\% opornością (11), natomiast według szeroko zakrojonych badań przeprowadzonych w latach 2004-2013 oporność inwazyjnych oraz nieinwazyjnych szczepów Streptococcus pneumoniae wynosiła $1,2 \%(13)$.

Obniżoną wrażliwość Streptococcus pneumoniae na meropenem (MIC $>0.25 \mathrm{mg} / \mathrm{ml})$ uzyskano w jednym przypadku $(\mathrm{MIC}=0.5 \mathrm{mg} / \mathrm{L})$, co stanowi 3,7\% badanych szczepów i jest to podobny odsetek do prezentowanego w raporcie BiNet (5\%) (9) i jednocześnie znacznie mniejszy od danych zebranych w międzynarodowej analizie (10\%), która jednak obejmowała szczepy wyhodowane $\mathrm{z}$ różnych postaci klinicznych zakażeń (13).

Wszystkie szczepy wykazywały wrażliwość na wankomycynę, co jest zgodne z innymi obserwacjami (14), (13). Natomiast niewrażliwość na kotrimoksazol dotyczyła $26,3 \%$ badanych szczepów. W pracy opublikowanej przez szwajcarskich badaczy opartej na inwazyjnych szczepach pochodzących od pacjentów w wieku od 5-64 lat zebranych pomiędzy 2004-2014 rokiem, przedstawiono $14,4 \%$ odsetek szczepów opornych (MIC $\geq 4 \mathrm{mg} / \mathrm{ml}$ ) na kotrimoksazol (12). Wysoką oporność notuje się w Afryce, szczególnie wśród pacjentów zakażonych wirusem HIV, którzy otrzymują trimetoprim z sulfametoksazolem w profilaktyce oportunistycznych zakażeń. W tej grupie oporność inwazyjnych szczepów Streptococcus pneumoniae wynosi 84\% (15).

\section{WNIOSKI}

Najczęstszym czynnikiem etiologicznym bakteryjnego ZOMR, zarówno w grupie wiekowej $>50$ lat, jak i 20-50 lat, jest Streptococcus pneumoniae (36,5\%). Neisseria meningitidis była częściej izolowana u osób w wieku 20-50 lat, natomiast Staphylococcus aureus oraz pałeczki Gram-ujemne >50 roku życia. W przedstawionej pracy wszystkie szczepy Streptococcus pneumoniae wykazywały wrażliwość na wankomycynę, linezolid, lewofloksacynę, rifampicynę i chloramfenikol. Wysoki odsetek szczepów charakteryzowała wrażliwość wobec ceftriaksonu $(97,2 \%)$ i meropenemu $(96,4 \%)$. Oporność na penicylinę wykazano u 27,8\% szczepów. 
Acad. Indus. Res 2013;1, 12:761-765.

4. Bhimraj A. Acute community-acquired bacterial meningitis in adults: An evidence-based review. Cleve Clin J Med 2012;79, 6:393-400.

5. Brouwer MC, Tunkel AR, van de Beek D. Epidemiology, Diagnosis, and Antimicrobial Treatment of Acute Bacterial Meningitis. Clin Microbiol Rev 2010;23, 3:467-492.

6. Amaya-Villar R Garc'ia-Cabrera E, SulleiroIgual $\mathrm{E} \mathrm{i}$ in. Three-year multicenter surveillance of community-acquired Listeria monocytogenes meningitis in adults. BMC Infect Dis 2010:10, 324.

7. Dzupova O, Rozsypal H, Smiskova D, et al Listeria monocytogenes Meningitis in Adults: The Czech Republic Experience. BioMed Research International 2013;1-4.

8. van de Beek D, de Gans J, Tunkel AR, et al. Community-Acquired Bacterial Meningitis in Adults. N Engl J Med 2006; 354:44-53.

9. Skoczyńska A, Kuch A, Sadowy E, i in. Recent trends in epidemiology of invasive pneumococcal disease in Poland. Eur J Clin Microbiol Infect Dis 2015;34, 4:779-87.

10. The European Centre for Disease Control and Prevention. Antimicrobial resistance surveillance in Europe 2015. Annual Report of the European Antimicrobial Resistance Surveillance Report (EARSS-Net) 2017;56-61.

11. 1liyasu G, Habib AG, Mohammad AB. Antimicrobial Susceptibility Pattern of Invasive Pneumococ- cal Isolates in North West Nigeria. J Glob Infect Dis 2015;7, 2:70-74.

12. Hauser C, Kronenberg A, Allemann A, et al. Serotype/serogroup-specific antibiotic nonsusceptibility of invasive and non-invasive Streptococcus pneumoniae, Switzerland, 2004 to 2014. Euro Surveill. 2016;21(21):pii=30239.

13. Hoban DJ, Reinert RR, Bouchillon SK, et al. Global in vitro activity of tigecycline and comparator agents: Tigecycline Evaluation and Surveillance Trial 2004-2013. Ann Clin Microbiol and Antimicrob 2015;14:27.

14. Gosciminski M, Bandy U, Luther K. The Changing Epidemiology of Invasive Pneumococcal Diseaseafter the Introduction of Pneumococcal Conjugate Vaccine, Rhode Island, 1997-2016. R I Med J 2017;57-59.

15. Soeters HM. von Gottberg A, Cohen C, et al Trimethoprim-Sulfamethoxazole Prophylaxis and Antibiotic Nonsusceptibility in Invasive Pneumococcal Disease. Antimicrob Agents Chemother 2012;56, 3:1602-1605.

Received: 6.03.2018

Accepted for publication:15.05.2018

Otrzymano: 6.03.2018 r.

Zaakceptowano do publikacji: $15.05 .2018 \mathrm{r}$.

Address for correspondence:

Adres do korespondencji:

mirecka@op.pl 